Bhúmi, The Planning Research

Journal Vol.07, No.02, 2020

\title{
Editorial
}

\section{Readings and workings on evolving urban built environments}

The Bhumi is present again after one year of locked-up conditions. Just as all living beings in this world, this journal too has to experience a difficult time with the ongoing Corvid-19 pandemic. However, the editors are of the view that pandemics are nothing but another type of force that drives the evolution of built environments.

Urban environments are in a continuous process of evolution. The process is non-reversible, the changes are inevitable, their implications are multi-faceted and the inhabitant's adaptations to the situations surging form this change are essentially not smooth. The struggle to live with changing situations compelled human beings, both individuals and societies, either to react in aggressive modes or to respond with innovative measures.

This issue of Bhumi brings in four readings on four different means of responses to such evolutions in urban built environments. Even though the cases presented in the papers are from South Asian cities, the situations presented in them are reflective of issues common to all urban areas around the world.

The graffiti on walls in public places are not rare in many cities, but their presence is received by respective societies and their sub groups with mixed responses, depending in the value structure of the inhabitants. Graffiti has been used both to disguise the underlying apathy of the state of affairs and to express the anger of the suppressed. In the first, the respective city administrators are likely to pose supportive gestures, while in the second, they often to launch oppressive measures. The direction in which this duality leads the built environments in their evolution is undoubtedly of interest to all those who engage in the urban discourse. In that sense, Suneela and Norman Ahmed's study on the graffiti on the walls in Karachi's public spaces is a classic example to demonstrate the power of this expressive form of public art (even though some may object to call this an 'art').

Floods have become common events in many cities around the world, but their presence has been felt when they cause sizeable damages to communities and their properties. The occurrence and the vulnerability are essentially aggravated with the increase of physical developments in urban areas.

Flood related damage can be minimized in two different approaches. The first approach deals with the management of the potential risk. In this approach, the current innovations in information technology can play a decisive role. The presentation on the use of Open Street Map Application for the Flood Risk Assessment, by S Suthakaran and his team, demonstrated with the situations in Manmunai-North area in the Batticaloa district in Sri Lanka, is an example for such initiative with possible engagement with the community, and with the use of common, but smart mobile phone based applications. 
The other approach is the 'prevention', which is always regard better than cure. Hence, planning the built environment in advance for storm water management is as important as mitigation in order to avoid flood related hazards. The urbanization of the land uses and the resulting changes in the landscapes and the land form, inevitably modify the quality, quantity and the flow patterns of surface runoff, and result in adverse situations, unless appropriate design strategies had been sought in the planning of such land use changes. Alternatives and supplementary systems can be inbuilt to the spatial strategies of planning-built environments for sustainable developments. Yet, the selection of the most appropriate alternative, from among many available, is a decision governed by the geographic conditions of the respective locations in one hand, and the financial and institutional capabilities of the infrastructure development agencies on the other. The framework to select a sustainable storm water management option for urban areas, presented by the team work lead by U.P.L.V. Pathirana, in the third paper and the methodology suggested therein, demand the attention of the authorities engaged in management of the changing built environments.

Another form of change experienced by many urban areas is the 'gentrification'. Gentrification is a process commonly observed in almost all post-modern cities around the world, irrespective of their economic or socio-cultural status. Gentrification has also got many definitions, but for many of them, the demand caused for more strategically located, better advantaged, and uniquely positioned lands and properties by socially more affluent groups characterize the process. The core concept of gentrification, i.e., replacing the dominance of an existing community from an area where they had been rooted for long periods, by new comers those who exhibit different sets of socio-economic values, relationships, and behavioral attributes, has been adopted by other studies in order to explore new socio spatial dimensions of the evolution of urban areas. Among them 'studentification', is a term popularly associated with the gradual changes observed in the socio-spatial order in the built environments around major universities. As a concept, the 'studentification', subject to the last paper, co-authored by D. Shanmugarajah and the others, share many similarities with the widely discussed 'gentrification', but in terms of core values associated with property rights and the authoritative dominant engagement in space, the role played by the students in evolving the subject physical environment is not as strong as in case of common gentrification.

However, these four papers have contributed valuable substance for a few on-going and longterm research projects that engaged multiple facets of the changing urban environments, while providing some interesting thoughts to the readers of Bhumi.

\section{Dr. Jagath Munasinghe}

\section{Editor in Chief}

